\title{
Deaths after peritoneal lavage with mercuric chloride solutions: case report and review of the literature
}

\author{
TREVOR LAUNDY, ANDREW E ADAM, JOHN B KERSHAW, DAVID J RAINFORD
}

Mercuric chloride solutions have been used in operations for over 30 years in attempts to kill cancer cells implanted on healthy tissue. Three applications have emerged. The most common is the use of $1 / 500$ and $1 / 1000$ solutions to wash out the bowel lumen during operations for colorectal carcinoma. ${ }^{1-3}$ The second is simple wound irrigation to prevent recurrences in the scar, particularly in breast cancer. ${ }^{4}$ The third is intraperitoneal application where seeding of a visceral cancer is feared. ${ }^{1-3} 5$ All these applications carry the theoretical risk of mercury absorption and nephrotoxicity. Documented examples of acute renal failure and death have occurred after-peritoneal lavage $^{6-9}$ and include two cases from this unit. ${ }^{10}$ The first (unpublished) death after peritoneal lavage was reported to the Committee on the Safety of Medicines in 1977.

We report the 10th case of a serious adverse reaction-and the fifth known death-after peritoneal lavage with a mercuric chloride solution and review other published cases.

\section{Case history}

A previously well 53 year old woman presented with a six week history of abdominal pain. Laparotomy disclosed a $6 \mathrm{~cm}$ solid ovarian tumour with a fluid filled cystic component. Its appearance suggested malignancy, and histological examination confirmed a poorly differentiated serous cystadenocarcinoma. During removal the cyst ruptured and peritoneal lavage with $500 \mathrm{ml} 1 / 500$ mercuric chloride was performed. After five minutes all visible fluid was carefully removed by suction and thorough swabbing. No abnormality of the peritoneal or serosal surfaces was noted, and haemostasis was satisfactory. The operation was completed uneventfully.

Twelve hours later the patient became suddenly hypotensive (blood pressure $80 / 60 \mathrm{~mm} \mathrm{Hg}$ ) with a temperature of $39 \cdot 5^{\circ} \mathrm{C}$. $\mathrm{Her}$ urine output decreased, and she passed blood per rectum. Haemoglobin concentration was $18.9 \mathrm{~g} / \mathrm{dl}$ and peripheral white cell count $15 \cdot 4 \times 10^{9} / 1$. After an infusion of isotonic saline and human plasma protein fraction her blood pressure stabilised at $140 / 80 \mathrm{~mm} \mathrm{Hg}$, which suggested a return to normal intravascular volume. Three successive blood cultures grew no pathogens, and her fever disappeared without antimicrobial treatment. Nevertheless, she developed ascites and became completely anuric, remaining so despite challenges with intra-

\footnotetext{
Department of Renal Medicine, Princess Mary's Royal Air Force Hospital Halton, Aylesbury, Bucks HP22 5PS

TREVOR LAUNDY, BSC, MRCP, senior specialist in medicine

DAVID J RAINFORD, MRCP, consultant in renal medicine

Department of Histopathology, Royal Air Force Institute of Pathology and Tropical Medicine, Royal Air Force Halton, Aylesbury, Bucks HP22 5PS

ANDREW E ADAM, MRCPATH, consultant histopathologist

JOHN B KERSHAW, $M B$, CHB, senior specialist in pathology

Correspondence to: Dr Trevor Laundy.
}

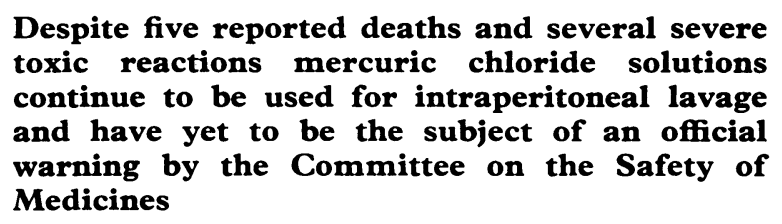

Despite five reported deaths and several severe toxic reactions mercuric chloride solutions continue to be used for intraperitoneal lavage and have yet to be the subject of an official warning by the Committee on the Safety of Medicines

venous frusemide and mannitol. By the third postoperative day her serum urea concentration had risen to $31.5 \mathrm{mmol} / 1(190 \mathrm{mg} / 100 \mathrm{ml})$, serum creatinine to $690 \mu \mathrm{mol} / 1(7.8 \mathrm{mg} / 100 \mathrm{ml})$, and serum potassium to $5.4 \mathrm{mmol}(\mathrm{mEq}) / 1$. Blood taken on the second postoperative day contained a mercury concentration of $2750 \mu \mathrm{g} / \mathrm{l}(13.7 \mu \mathrm{mol} / \mathrm{l})$. The normal value in this laboratory in non-exposed subjects is less than $15 \mu \mathrm{g} / \mathrm{l}$ (less than $0.07 \mu \mathrm{mol} / \mathrm{l}$ ).

The patient was transferred to our unit for haemodialysis. Because of pulmonary oedema she was transfused with salt poor albumin, and fluid was removed by ultrafiltration. She developed signs of adult respiratory distress syndrome and deteriorated despite intermittent positive pressure ventilation with positive end expiratory pressure. She died on the sixth postoperative day.

At necropsy there were large bilateral pleural effusions and the lungs were heavy, plum coloured, and oedematous. The peritoneal cavity contained 21 of free fluid and there was a severe pancolitis with ulceration. The kidneys were pale and swollen. Histological examination confirmed the features of adult respiratory distress syndrome, with patchy bronchopneumonia, necrotising colitis, and acute renal tubular necrosis. Tissues and fluids were taken for mercury estimations (table I). Subsequent analysis of the batch of mercuric chloride solution used peroperatively showed the concentration to be correct to within $1 \%$.

TABLE I-Mercury concentrations in tissues at necropsy. Values are $\mu \mathrm{g} / \mathrm{l}^{*}$

\begin{tabular}{lrrrrr}
\hline & Blood & Heart & Kidney & Lung & Liver \\
\hline Present patient $^{\text {Normal11 }}$ & 6000 & 3400 & 53000 & 5500 & 30000 \\
& 15 & 200 & 1100 & 280 & 800
\end{tabular}

*1 $\mu \mathrm{g} / 1 \approx 0.005 \mu \mathrm{mol} / 1$.

\section{Review and discussion}

Acute mercury poisoning is largely confined to occupational exposures, ${ }^{12}$ accidental ingestion by children, ${ }^{13}{ }^{14}$ and suicides. Bichloride of mercury, as used in surgical irrigation, is more soluble than mercurous salts and more dangerous, and sporadic warnings against its use specifically for peritoneal lavage have appeared over many years. In 1961 Keynes warned that mercuric chloride was too toxic for intraperitoneal use, though he personally once used a $1 / 500$ solution without adverse effect. ${ }^{1}$ In 1965 Schreiner and Maher, reviewing the pathogenesis of toxic nephropathies, stated: "The use of mercuric salts in douching and surgical irrigation should be discouraged."12 
Although beyond the scope of this paper, it should be noted that doubts have been raised about the unique efficacy of mercuric chloride solutions as cytotoxic agents. Both $1 \%$ cetrimide $^{4}$ and nitrogen mustard $2 \%$ in saline have been preferred by some authorities. ${ }^{15}$

In 1967 Gingell et al reported the first documented case of acute renal failure after peritoneal lavage. ${ }^{6}$ In 1970 Gibson et al advised generally against the solutions within the peritoneal cavity, and especially in patients with renal impairment. ${ }^{4}$ The first death in Britain was notified to the Committee on the Safety of Medicines in 1977 (personal communication), and another was notified to the Netherlands Centre for Monitoring Adverse Drug Reactions and described in 1978. ${ }^{7}$ In 1979 Pusey et al from our unit reported successful haemodialysis of two patients after lavage, one of whom later developed a nephrotic syndrome. ${ }^{10}$ In the same year Cross et al described three poisonings as a result of lavage, two of them fatal. ${ }^{8}$ They emphasised that one litre of the commonly used $1 / 500$ solution contains $2 \mathrm{~g}$ mercury-twice the normally accepted lethal dose. In 1983 Lai et al reported oliguric renal failure and recovery in a 64 year old man after lavage with a $1 / 500$ solution during hemicolectomy. ${ }^{9}$

Our report brings the total of severe adverse reactions to mercuric chloride solution used for peritoneal lavage to 10 , of which five have been fatal (table II). Probably many other cases go undetected, either because they are subclinical or because the biochemical diagnosis is simply never considered and a blood or urine mercury estimation is not ordered. Postoperative mercury poisoning is manifested predominantly by circulatory collapse followed by oliguric renal failure, a combination which may be attributed wrongly to adverse reaction to anaesthetic, Gram negative shock, or internal haemorrhage. In one case the patient was submitted to a second laparotomy for suspected bleeding before the correct diagnosis was made. ${ }^{8}$

Mercuric chloride solutions are also used to irrigate the bowel lumen during cancer surgery and have been shown to reduce recurrences in the suture line and locally. ${ }^{116}$ To our knowledge no toxic reactions have been reported to this procedure, although increased urinary excretion of mercury has been reported. ${ }^{5}$

These solutions are also used for wound irrigation, and a serious toxic reaction was described after irrigation of a nephrectomy wound. ${ }^{17}$ In one series of 21 patients with various operation sites irrigated raised urinary concentrations of mercury were reported in an unspecified number, and in two the value exceeded $300 \mu \mathrm{g} / \mathrm{l}(1.495 \mu \mathrm{mol} / \mathrm{l}) .^{4}$

The possibility of toxic absorption is apparently inherent in all three irrigation procedures, although the risk appears to be significant only with peritoneal lavage-presumably because of the greater absorption area and special characteristics of the peritoneal membrane. Our patient died because she absorbed a large quantity of inorganic mercury during or after peritoneal lavage. The precise mechanism of absorption in these circumstances is uncertain; some workers regard it as a rare idiosyncratic reaction in patients who develop a chemical peritonitis as a type 1 hypersensitivity reaction, since inflamed peritoneal surfaces are highly permeable. Alternatively there may be embolism of fluid containing mercury or rapid absorption across a previously inflamed peritoneum. In other cases it is more likely that fluid is simply left inside the cavity either by intention or by incomplete removal and is slowly absorbed.

The clinical picture of acute mercury poisoning in our patient was characteristic. ${ }^{2}$ It includes sudden, profound circulatory collapse with tachycardia, hypotension and peripheral vasoconstriction, vomiting, and bloody diarrhoea. The latter is due to a haemorrhagic colitis and may be a useful diagnostic feature, as may a metallic taste in the mouth of a conscious patient. Renal failure usually develops within 24 hours and is associated with albuminuria, epithelial cell casts and red cells in the urine, glycosuria, and aminoaciduria. Oliguria may proceed to complete anuric failure. There is a neutrophil leucocytosis of up to $20 \times 10^{6} / 1$ due to tissue necrosis.

Histologically the classic renal lesion of acute mercury poisoning lies in the terminal part of the proximal tubule. Mercury ions are probably specifically concentrated there and have a direct toxic effect on the cell membrane. ${ }^{18}$ In fatal cases the tubular epithelial cells show a spectrum of degeneration, fragmentation, and necrosis with areas of bared basement membrane. The tubular lumen is blocked by large casts and granular debris. There is variable interstitial oedema but no consistent vascular or glomerular changes.

Mercury is also widely taken up by body tissues, so that in fatal cases other organs may show non-specific changes-for example, colitis, liver necrosis, and cerebral petechial haemorrhages. Death in our patient was attributed not to renal failure, for which appropriate and adequate treatment was instituted, but to adult respiratory distress syndrome and bronchopneumonia. Heavy metals are a recognised cause of this syndrome, and the concentration of mercury in her lung tissue was 20 times normal.

Certain common features were present in the patients who experienced adverse reactions (table II). Where details are known, all were middle aged or elderly, though fit enough for attempted curative rather than palliative operations for cancer. Mercuric chloride solutions varying in strength from $1 / 2000$ to $1 / 500$ were used. In one case death occurred after the use of a solution containing as little as $400 \mathrm{mg}$ mercuric chloride. Besides displaying the clinical features of mercury poisoning described above, many of the patients showed early signs of

TABLE II-Adverse reactions to peritoneal lavage with mercuric chloride solutions

\begin{tabular}{|c|c|c|c|c|c|c|}
\hline Reference & $\begin{array}{l}\text { Year of } \\
\text { report }\end{array}$ & $\begin{array}{l}\text { Age and } \\
\text { sex }\end{array}$ & Operation/disease & $\begin{array}{l}\mathrm{HgCl}_{2} \text { solution } \\
\text { used }\end{array}$ & Renal consequences & Outcome \\
\hline Gingell et $a l^{6}$ & 1967 & $68 \mathrm{~F}$ & $\begin{array}{l}\text { Ovarian cystectomy; } \\
\text { mucinous cystadenoma }\end{array}$ & $250 \mathrm{ml}, 1 / 500$ & Immediate severe oliguria & $\begin{array}{l}\text { Haemodialysis for } 2 \frac{1}{2} \text { months; some impairment } \\
\text { of renal function at } 5 \text { months }\end{array}$ \\
\hline $\operatorname{CSM}^{*}$ & 1977 & $69 M$ & Gastrectomy; carcinoma & $400 \mathrm{mg} \mathrm{HgCl}_{2}$ & $\begin{array}{l}\text { Acute renal failure } \\
\text { within } 24 \mathrm{~h}\end{array}$ & Died after 10 days \\
\hline \multirow[t]{2}{*}{ Meyboom ${ }^{7}$} & 1978 & $59 \mathrm{~F}$ & $\begin{array}{l}\text { Ovarian cancer with } \\
\text { local spread }\end{array}$ & $21,1 / 1000$ & Renal failure in $2 \mathrm{~h}$ & $\begin{array}{l}\text { Dimercaprol and haemodialysis; died } 2 \text { days } \\
\text { postoperatively }\end{array}$ \\
\hline & & & "Cancer" & Not stated & $\begin{array}{l}\text { Acute renal failure in } \\
\text { under } 24 \mathrm{~h}\end{array}$ & Died \\
\hline \multirow[t]{2}{*}{ Cross et $a l^{8}$} & 1979 & Not stated & "Cancer" & Not stated & $\begin{array}{l}\text { Acute renal failure in } \\
\text { under } 24 \mathrm{~h}\end{array}$ & Died \\
\hline & & Not stated & “Cancer" & Not stated & $\begin{array}{l}\text { Acute renal failure in } \\
\text { under } 24 \mathrm{~h}\end{array}$ & Survived \\
\hline \multirow{2}{*}{ Pusey et $a l^{10}$} & 1979 & $61 \mathrm{~F}$ & $\begin{array}{l}\text { Removal of ovarian cyst; } \\
\text { carcinoma of ovary }\end{array}$ & $1 / 2000$ & Renal failure in $48 \mathrm{~h}$ & $\begin{array}{l}\text { Survived with nephrotic syndrome (remitted } \\
\text { after } 6 \text { months) }\end{array}$ \\
\hline & 1979 & $50 \mathrm{~F}$ & $\begin{array}{l}\text { Hemicolectomy; carcinoma } \\
\text { of descending colon }\end{array}$ & $1 / 500$ & $\begin{array}{l}\text { Oliguria with low } \\
\text { osmolality }\end{array}$ & Survived after 6 days' haemodialysis \\
\hline Present case & 1984 & $53 \mathrm{~F}$ & $\begin{array}{l}\text { Oophorectomy (ovarian } \\
\text { cancer) }\end{array}$ & $500 \mathrm{ml}, 1 / 500$ & Acute renal failure in & Haemodialysis; died 6 days postoperatively \\
\hline Lai et $a l^{\circ}$ & 1983 & $64 M$ & Carcinoma of bowel & $1 / 500$ & $\begin{array}{l}\text { Renal failure } 4 \text { days } \\
\text { after operation }\end{array}$ & $\begin{array}{l}\text { Haemodialysis for } 12 \text { days; renal function normal } \\
\text { after } 4 \text { months }\end{array}$ \\
\hline
\end{tabular}

*Committee on the Safety of Medicines (case No 54948). 
peritonitis and ascites. Oliguric or anuric renal failure usually developed within a few hours in the most severe (fatal) cases, but may be of delayed onset in patients who survive. Where treatment is described, all patients received haemodialysis and some received dimercaprol, though the value of this agent may be questionable unless given early. ${ }^{72}$ Of the survivors, one had a nephrotic syndrome and another renal impairment five months after lavage.

\section{Conclusion}

Despite accumulated warnings over many years the use of mercuric chloride solutions (which have never been the subject of a warning notice from the Committee on the Safety of Medicines) persists in Britain. An informal survey of pharmacies at major London centres showed that five out of 14 contacted were currently supplying these solutions for intraperitoneal use. The question of efficacy apart, the accumulated experience of 10 severe toxic reactions including five deaths suggests that the use of mercuric chloride for peritoneal lavage is too dangerous and should be abandoned.

We thank the Director General Medical Services (RAF) for permission to publish. We also thank $\mathrm{Mr}$ I M House, of the poisons unit at Guy's Hospital, for the mercury estimations.

\section{References}

' Keynes WM. Implantation from the bowel lumen in cancer of the large intestine. Ann Surg 1961;153:357-64.

Goligher JC, Dukes CE, Bussey HJR. Local recurrences after sphincter saving excisions for carcinoma of the rectum and rectosigmoid. Br $\mathcal{F}$ Surg $1951 ; 39$ 199-211.

Naunton MC. Trends in the treatment of tumours of the rectum, rectosigmoid and left colon. I $R$ Coll Surg Edinb 1955;1:112-25.

mon GR, Lawrence KB, Stephens FO. Comparison of the use of cetrimide, mercuric chloride and other irrigant solutions in eradicatin

5 Devlin HB. Mercuric perchloride in surgery of bowel cancer. Br Med 71967 ;iii: 679 .

Gingell JC, Cle.

Meyboom RHB. Metals. In: Dukes MNG, ed. Side effects of drugs annual 2. Amsterdam: Excerpta Medica, 1978:205-11.

Cross JD, Dale IM, Elliot HL, Smith H. Postoperative mercury poisoning Med Sci Law 1979;19:202-4.

Lai KN, Pugsley DJ, Black RB. Acute renal failure after peritoneal lavage with mercuric chloride. Med F Aust $1983 ; \mathrm{i}: 37-8$.

- Pusey CD, Kennedy ND, Rainford DJ. Mercury nephrotoxicity from peritoneal lavage. Br F Surg $1979 ; 66: 200$

Yukawa M, Susuki YM, Amano K, Terai M. Distribution of trace elements in the hum.

12 Schreiner GE, Maher JF. Toxic nephropathy. Am 7 Med 1965;38:409-49.

Stack T, Bissenden JG. Hoxic nephropathy. Am W Med 1965,38:409-49. month old child. Br Med $\mathcal{F} 1983 ; 287: 1513$.

14 Samuels ER, Heick HM, Maclaine PN, Farrany JP. A case of accidental inorganic mercury poisoning. $\mathcal{F}$ Anal Toxicol $1982 ; 6: 120-2$.

15 Goligher JC. Surgery of the anus, rectum and colon. 2nd ed. London: Baillière, Tindall and Cassell, 1967:536-41.

Goligher JC. Resection with restoration of continuity for rectal cancer. In: Robb C, Smith R, eds. Operative surgery. Vol 3. London: Butterworths, 1953:83-96.

${ }^{17}$ Royle JP. A case of mercury poisoning following the use of perchloride of mercury. Aust NZ F Surg 1964;34:71-2.

Gonote CE, Reimer KA, Jennings RB. Acute mercury poisoning-an electron
microscopic and metabolic study. Lab Invest $1974 ; 3(\mathrm{pt} 6): 633-47$.

(Accepted 29 March 1984)
What features distinguish chronic persistent hepatitis from chronic inactive hepatitis? Do steroids play any part in the treatment of persistent hepatitis?

Chronic persistent hepatitis is defined histologically as a mononuclear cell infiltrate confined to expanded portal tracts. If inflammation extends into the hepatic parenchyma with piecemeal necrosis the lesion is chronic active hepatitis. Biochemical indices such as high serum aminotransferase bilirubin and globulins and clinical features including spider naevi are usually more pronounced in chronic active hepatitis, but a liver biopsy is essential to distinguish between the two forms. Chronic persistent hepatitis may follow an episode of acute hepatitis or may arise insidiously and is of two main types: that associated with hepatitis $B$ virus infection and that where no cause can be identified. Its progression to cirrhosis is rare and corticosteroids are not indicated. A few patients, however, may progress to chronic active hepatitis, particularly after hepatitis B, and a repeat biopsy at two year intervals is recommended. Of two main varieties of chronic active hepatitis, one is associated with hepatitis $B$ virus infection and the other is an autoimmune condition for which corticosteroids, often with azathioprine, are recommended. Once remission has been achieved in autoimmune chronic active hepatitis, the biopsy appearance may resemble the persistent form or there may be fibrosis alone. The prognosis of chronic persistent hepatitis in these circumstances is more guarded than when it arises de novo. Once in remission, the dose of corticosteroids is usually reduced but complete withdrawal of corticosteroids may be hazardous, with a high rate of relapse, and maintenance treatment is recommended. Chronic active hepatitis secondary to hepatitis $B$ virus infection is much more difficult to treat, although some encouraging results are now being obtained with antiviral agents. The use of corticosteroids is restricted to those patients with histological evidence of continued activity after viral replication has ceased. These features represent an inactive phase of chronic active hepatitis, although chronic "inactive" hepatitis is not a generally accepted histological classification. Chronic persistent hepatitis arising de novo and that after spontaneous or corticosteroid induced remission are indistinguishable histologically, although the prognosis of the latter is more guarded than that of chronic persistent hepatitis arising de novo.-ROGER WILLIAMS, consultant physician and director of liver unit, London.

\section{What treatment is advised for intractable postherpetic neuralgia?}

There is no definitive treatment for postherpetic neuralgia. The pain arises because during the acute phase of shingles some or all of the large $A \beta$ nerve fibres in the skin are destroyed, leaving an excess of C-fibre stimulation, which produces chronic pain. ${ }^{1}$ In addition to pain there is usually some dysaesthesia. Classically, postherpetic neuralgia is more likely to develop in those aged over 60 (in those aged 80 and over about $80 \%$ ). Thus the older the patient the more vigorous the treatment, which should be undertaken at the earliest possible stage-that is, when the vesicles are first forming. At this stage, treatment is one or more of idoxuridine (Herpid) locally, sympathetic block, ${ }^{2}$ epidural steroid, or systemic steroids in large doses. For established cases, a series of treatments can be tried successively in the hope that one will be effective or partially effective. There is some chance of cure if the postherpetic neuralgia has been present for less than three months-at least some benefit may be hoped for. After six months the most that can be hoped for is some alleviation. Exceptions do occur so the full range should be tried. The treatment used at this centre includes: (1) A cold spray (Boots PR Spray, Skefron), which should be used over the whole painful area three times, with a one minute interval between sprays. This is repeated each time the pain recurs severely. Try for one week at least. (2) Mixtures of a tricyclic antidepressant with a substituted phenothiazine, such as amitriptyline and fluphenazine, should be tried for one month. ${ }^{3}$ (3) $\mathrm{Up}$ to three sympathetic blocks may be tried. (4) Subcutaneous injections of local anaesthetic and long lasting steroid-for instance, methylprednisolone (Depo-medrone)-are often helpful in reducing severe dysaesthesia and may be repeated every three months or so. (5) Transcutaneous electrical nerve stimulation may be used indefinitely if beneficial. It works by increasing stimulation along residual $A \beta$ nerve fibres and, on the basis of the gate control theory, thus reduces pain. (6) Paravertebral blocks, using simple anaesthetics, neurolytic substances, or nerve destruction by radiofrequency current coagulation or the cryoprobe. (7) Intrathecal phenol is not advocated nowadays as its effects on pain are temporary and it rarely affects dysaesthesia; it can be dangerous.

Some of these techniques may be readily performed in general practice. Others are available at the local hospital pain relief clinic. One problem, however, will be the long waiting lists there. Nevertheless, it should be remembered that the earlier postherpetic neuralgia is treated, the better.-SAMPSON LIPTON, medical director, pain relief foundation, Liverpool.

' Melzack M, Wall PD. Pain mechanisms. A new theory. Science 1965;150:971. 2 Colding A. Section of anaesthesia 25-27. Proceedings of the Royal Society of Medicine 1973;66:541-3.

3 Taub A, Collins WF Jr. Observations on the treatment of denervation dysaesthesia with psychotropic drugs : post herpetic neuralgia, anaesthesia dolorosa, periphera neuropathy. In: Bonica JJ, ed. Advances in neurology. Vol 4. New York: Raven
Press, 1974:309-15. 